\title{
Micropore structure and water driving characteristics of tight sandstone reservoirs in Ordos Basin
}

\author{
Shuxun Zhou ${ }^{1,2} \cdot Y_{\text {Yan Zhou }}^{3} \cdot \operatorname{Jian} \mathrm{Shi}^{1,2}\left(\mathrm{Yujie} \mathrm{Zhu}^{4} \cdot\right.$ Wulin Xiao $^{5} \cdot$ Rui Zhang $^{6}$
}

Received: 23 July 2021 / Accepted: 28 September 2021 / Published online: 16 October 2021

(c) The Author(s) 2021

\begin{abstract}
In order to explore the influence of the micropore structure of the tight sandstone reservoir in the water driving characteristics, the studies on the Chang 6 tight sandstone reservoir of the middle-western part of Ordos Basin are carried out by various experiments such as cast-thin section analysis, scanning electron microscopy, high-pressure mercury injection and micro-water driving. The result shows that the permeability contribution curves of samples shift to the left as the sample permeability decreases, indicating that the greater the permeability, the greater the proportion of large pores. The permeability is mostly dominated by pores with the radius larger than $\mathrm{R}_{50}-\mathrm{R}_{60}$. There are big differences in the water driving type, oil-driven efficiency and residual oil distribution characteristics between reservoirs of different types. The type II reservoir is the major target of subsequent exploration and development, where water driving types consist of mesh and finger, leaving the residual oil mainly locked by water or isolated as oil drops. The size and distribution feature of pores are the key factors dominating the oil-driven efficiency.
\end{abstract}

Keywords Ordos Basin $\cdot$ Tight sandstone reservoir $\cdot$ Micropore structure $\cdot$ Water driving characteristics

\section{Introduction}

The exploration and development of tight gas and oil reservoir, the unconventional petroleum resources, occupies an increasingly important position in China's oil and gas exploration field (Fu et al. 2015; Yang et al. 2013, 2017; Zou, 2011). Ordos Basin has many sets of tight oil reservoirs, one

Jian Shi

shijian2371@163.com

1 Exploration and Development, Research Institute of PetroChina Changqing Oilfield Company, Xi'an 710018, Shaanxi, China

2 National Engineering Laboratory for Exploration and Development of Low-Permeability Oil and Gas Fields, Xi'an 710018, Shaanxi, China

3 CNPC Logging Applied Research Institute, Xi'an 710077, China

4 No. 2 Gas Production Plant, Changqing Oilfield Company, PetroChina, Yulin 719000, China

5 Fengcheng Oilfield Operation Area of PetroChina Xinjiang Oilfield Company, Karamay 834000, Xinjiang, China

6 No. 1 Gas Production Plant, Changqing Oilfield Company, PetroChina, Yulin 718500, China of which is the Yanchang formation reservoir. Its pore structure is pretty complex, with the pore size ranging from micro to nano (Zou et al. 2009; Zou et al. 2012; Li et al. 2015b, a), bringing water-injection practice some negative effects such as the low water driving efficiency. In fact, these problems, mainly caused by differences of fluids movement, are comprehensive reflections of both the micropore structure and the migration of fluids at various phrase. In other words, the micropore structure and fluid properties of the reservoir are fundamental elements of these differences (Huang 2019a, b; You et al. 2014; Huang 2019a, b; Zhang et al. 2015). Domestic and foreign scholars believe that reservoir heterogeneity and wettability are the internal factors affecting water driving efficiency, while displacement pressure and injection ratio are the external factors affecting water driving efficiency. In recent years, with the application of electron microscopes in the petroleum industry (Zhang et al. 2017; Bai et al. 2018), more and more scholars gradually have realized that the relationship between the micropore structure and water driving characteristics. It is argued that the micropore structure of the reservoir has a significant impact on the water driving characteristics (Quan et al. 2011; Zhou, 2017), and the pore radius can better reflect the oil-driven efficiency and seepage characteristics of tight reservoirs. The

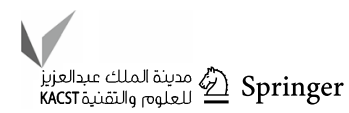


reservoir type divided by the micropore structure will be more accurate and practical.

The middle-western part of Ordos Basin crosses Yishan Slope and Tianhuan Depression. The Yanchang formation can be divided into 10 oil-bearing layers (Fig. 1), among which Chang 6 has suffered serious compaction and cementation, leading to tightness features of its sandstone and reservoir. The tightening results in the serious complexity of pore structure and the fluid seepage and distribution, which directly threatens its exploration and development. Previous studies on microscopic pore-throat structure and water driving characteristics of tight sandstone reservoirs are not comprehensive enough. In order to elaborately describe the water driving characteristics, various experiments such as cast-thin analysis, scanning electron microscopy and high-pressure mercury intrusion are used to reveal and classify the pore structure type. Then, combined with the micro-water driving model of real sandstone, the characteristics of water flooding are studied, and main factors of the micro-water driving efficiency are analyzed.

\section{Experimental methods and principles}

\section{High-pressure mercury injection}

The high-pressure mercury intrusion experiment is one of the most important methods to study the pore structure characteristics of tight sandstone reservoirs. In the experiment, mercury, the non-wetting phase is injected into a sandstone sample, and with the increase in injection pressure more and more mercury flows into the sample's pores. According to the capillary pressure formula, the pore radius under every pressure can be calculated, so as the mercury volume of entering the pore (Jia et al. 2014; Li et al. 2015b, a). The capillary pressure curve can be drawn from a series of data on the mercury's saturation and injection pressure. This curve can not only describe the distribution feature of connected pore of different radius of samples (Gao et al. 2011), but also reflect the relationship between porosity-permeability and the size distribution of pores. Auto Pore IV 9510 automatic mercury-injection instrument made by Mac Inc. is used in this experiment, and its maximum working pressure is $227 \mathrm{MPa}$, and the measurable pore radius ranges from 0.003 to $1000 \mu \mathrm{m}$.

\section{Micro-water driving experiment}

Firstly, sandstone samples are made into a thin slice model of about $2.5 \mathrm{~cm} \times 2.5 \mathrm{~cm} \times 0.05 \mathrm{~cm}$. According to the viscosity of crude oil and the salinity of formation water of the study area, the oil and water are formulated, and colorants of red and blue are, respectively, added to facilitate the distinction of them under the electron microscope. Under one certain pressure, the oil and water flow into the sample together. The seepage and driving process of oil and water are observed by the electron microscope, which can clearly reflect the moving characteristics of oil

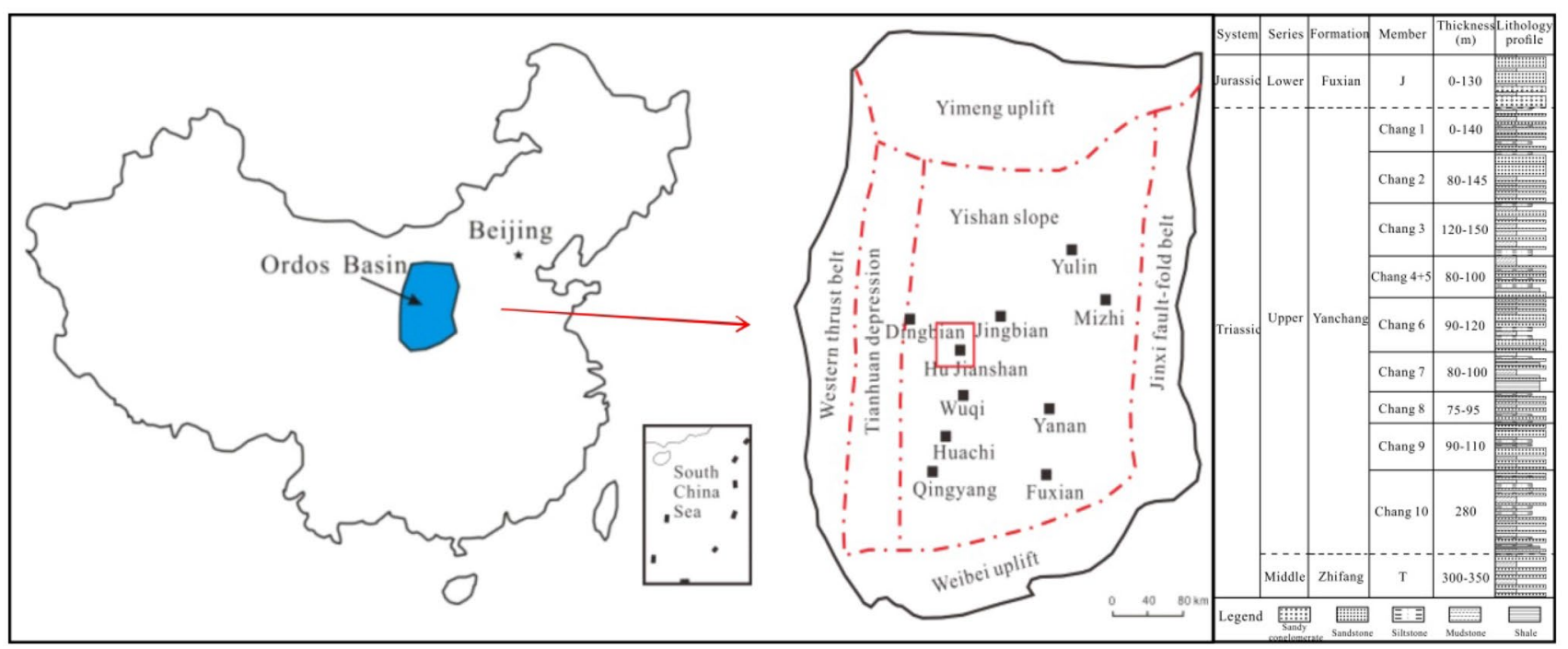

Fig. 1 Geographical location of study area, stratigraphic division of Yanchang formation 
and water in the micropore scale. The micro-water driving experiment is realized in the State Key Laboratory of Continental Dynamics of Northwest University through the real-sandstone micro-water driving equipment. It consists of electron microscope, pressure detection system, vacuum equipment and computer image acquisition system. The function of vacuum equipment is to extract air from the sample to make samples form a vacuum state. The pressure system is used to exert and measure the pressure at different stages and situations. The electron microscope is used to observe the state and distribution of oil and water all the time. The role of computer image acquisition is to capture details of the micro-movement of oil and water at different stages by cameras.

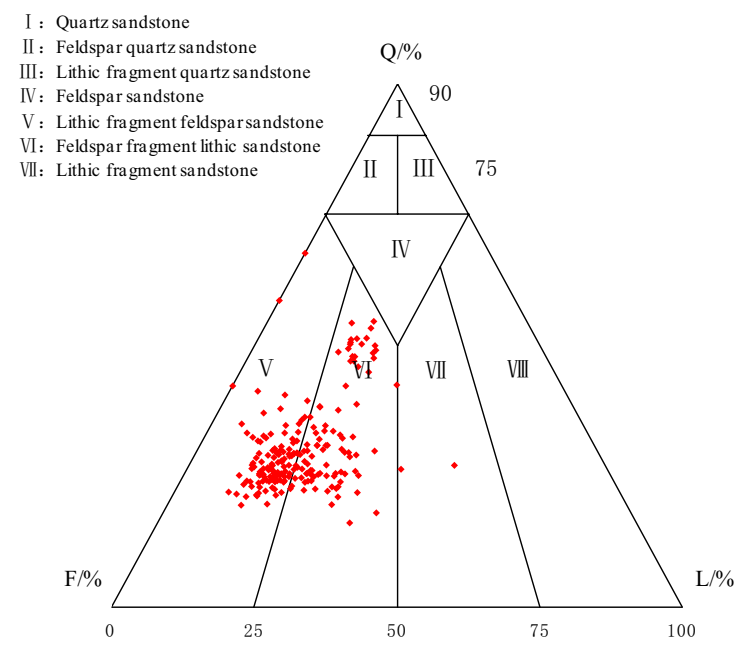

\section{Samples}

The Yanchang formation in the middle-western area of Ordos Basin deposits as a part of delta front subfacies. According to the observation of 196 core samples by the cast-thin section and scanning electron microscopy and the porosity-permeability analysis of 560 core samples, there are mainly two kinds of sandstone: the feldspar sandstone and the lithic-feldspar sandstone. The average content of quartz and feldspar is $25.2 \%$, and $45.4 \%$, respectively, and the content of lithic is relatively low, with an average of $9.2 \%$ (Fig. 2). The average porosity and permeability are $10.67 \%$ and $0.53 \times 10^{-3} \mu \mathrm{m}^{2}$ (Fig. 3). The matrix consists of chlorite (3.8\%), kaolinite (2.5\%), illite (1.7\%), iron calcite $(2.8 \%)$ and siliceous (1.2\%) (Table 1, Fig. 3). Pores mainly include intergranular pores $(3.25 \%)$, intergranular

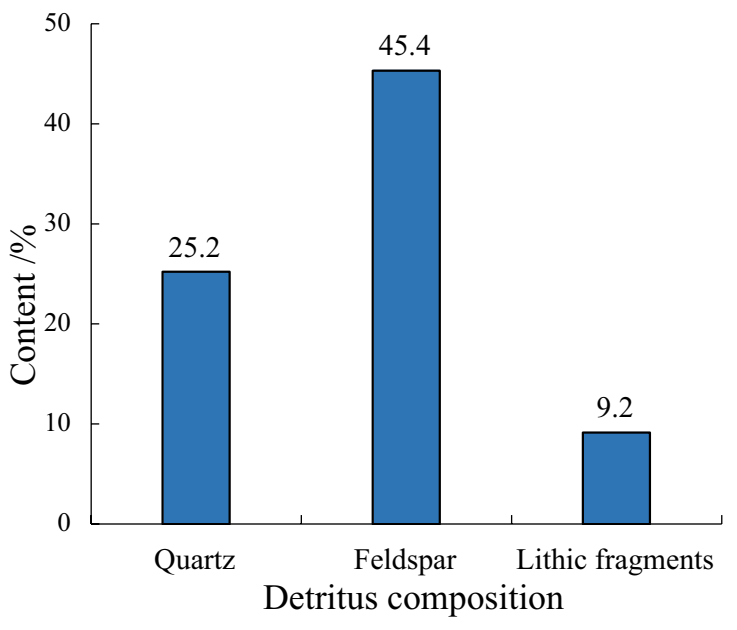

Fig. 2 Sandstone triangle diagram (left) and histogram of clastic composition distribution (right)
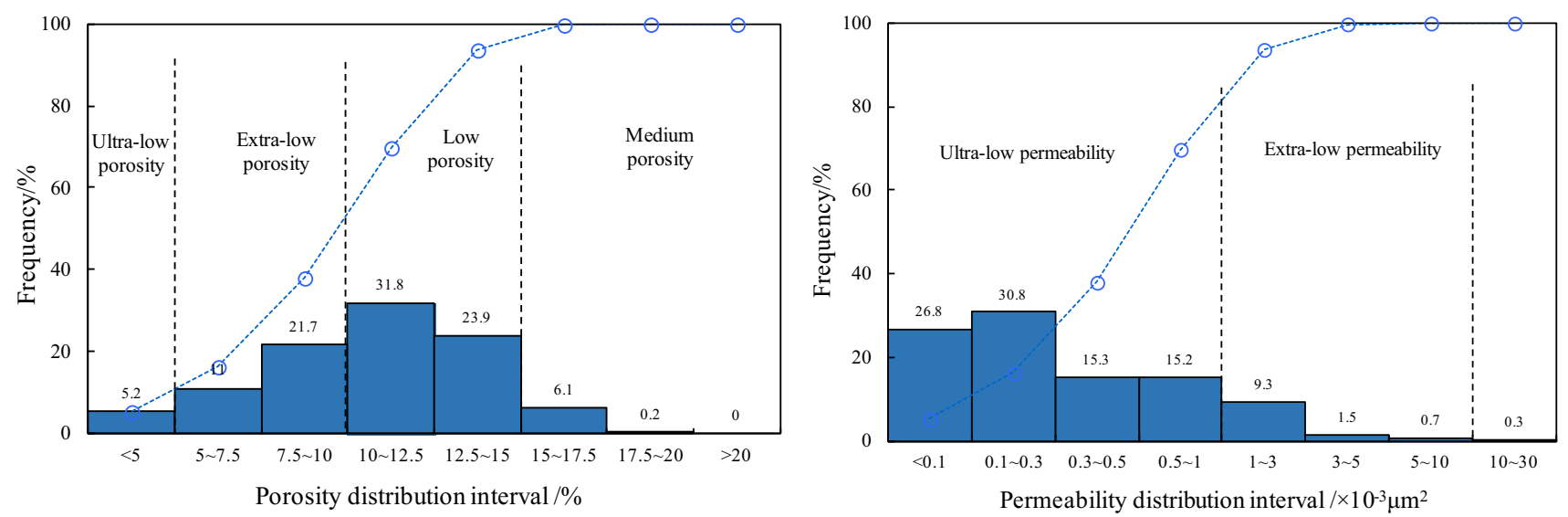

Fig. 3 Histogram of reservoir physical property distribution 


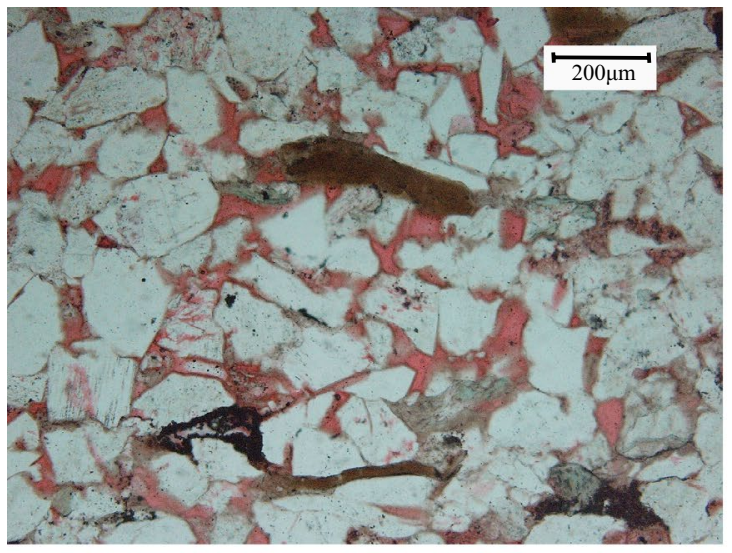

a. Intergranular pore development Y120, 2252.6m

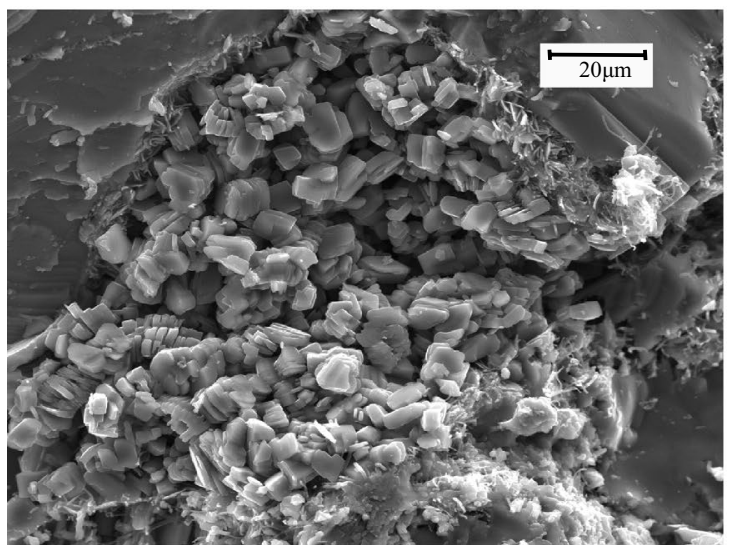

c. Intercrystalline pores in kaolinite filled with pores H156, 2056.1m

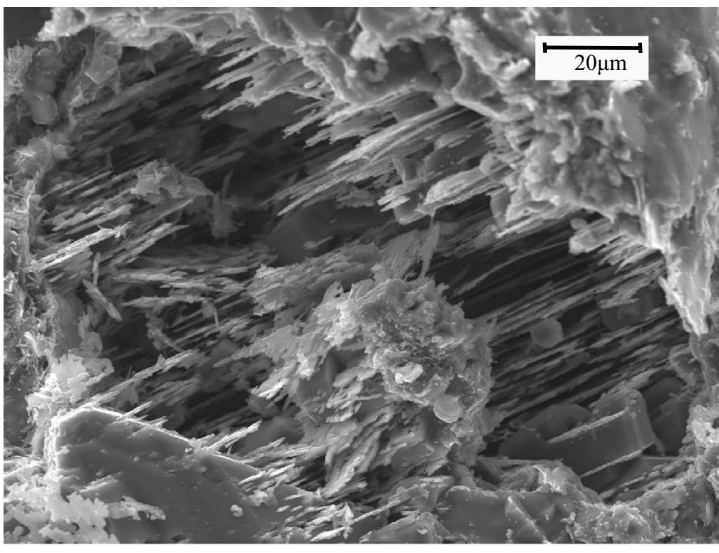

b. The dissolution pore of feldspar A97, 2054.6m

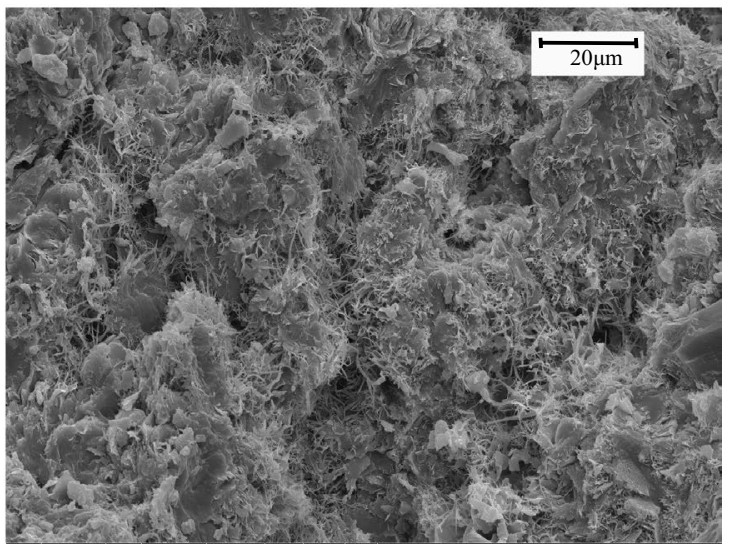

d. Intercrystalline pores of illite H68, 2378.6m

Fig. 4 Microscopic characteristics of pore types

dissolved pores $(0.02 \%)$, feldspar dissolved pores $(0.78 \%)$, lithic dissolved pores $(0.13 \%)$, intercrystalline pores $(0.12 \%)$, micro-cracks $(0.03 \%)$, with $4.33 \%$ in the average surface porosity and $35.62 \mu \mathrm{m}$ in the average pore diameter (Table 1, Fig. 3). Twenty-four samples are selected as subjects of high-pressure mercury-injection experiment, and 4 samples of different pore structure types are used for the micro-water driving experiment (Fig. 4).

\section{Discussion of experimental results}

\section{Pore structure}

According to the results of the high-pressure mercuryinjection experiment, the pore structure of Chang 6 reservoir can be divided into three types: I, II and III by pore parameters such as the threshold pressure, medium pressure, pore radius and maximum mercury saturation.
(1) Capillary pressure curves of type I mainly locate in the low-left area and show relatively low threshold pressures and micropores (Table 2, Fig. 5a). Sandstone of this kind has good quality of porosity and permeability. The pore types are mainly intergranular pores, dissolved pores, mainly forming sheet-shape seepage channels. When the mercury-inflow saturation and permeability contribution peak, their corresponding pore radius are all above $1 \mu \mathrm{m}$ (Fig. 5b), making type I the best reservoir in the study area.

(2) Capillary pressure curves of type II locate in the upperright area and are steeper than that of type I, with the threshold pressure higher than that of type I, showing the characteristics of medium threshold pressures and micropores (Table 2, Fig. 5a). Sandstone of this kind has mediocre quality of porosity and permeability. Its pore types are mainly dissolved pores and intergranular pores. Seepage channels mainly consist of lamellar pores. The pore radius of the max mercury-inflow 


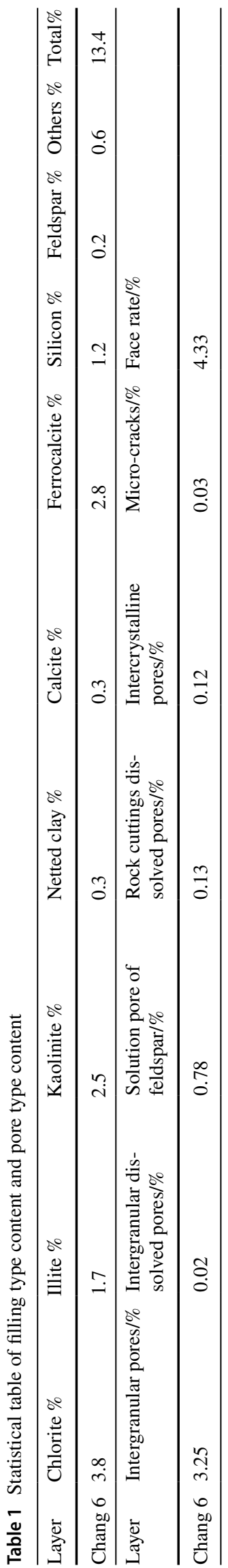

saturation and permeability contribution is between 0.5 and $1 \mu \mathrm{m}$ (Fig. 5c). It is the major target of further exploration and development in the study area for its good storage performance and seepage ability.

(3) Capillary pressure curves of type III locate in the most upper-right area and show the highest threshold pressures and micropores (Table 2, Fig. 5a). The porosity and permeability of this type sandstone are generally low, and its pores are mainly made up with dissolved pores and micropores, which are small radius after strong cementation. Later cementation resulted in serious damages to the pores: the bad pore-throat configuration, small amount of middle-radius pores and low mercury-injected saturation. The pore radius of the max mercury-inflow saturation and permeability contribution is between 0.1 and $0.5 \mu \mathrm{m}$ (Fig. 5d). The type III reservoir is bad in the performance of storing and seeping in the study area.

The mercury-injection process can be divided two stages (Fig. 5b-d). Initially, relatively large pores, having lower capillary forces, are the first places to be occupied with mercury. In spite of accounting for a small proportion of pore volume, these pores, however, play a vital role in permeability for the cumulative permeability contribution surges up to $98 \%$. And the cumulative mercury saturation is also increasing rapidly up to a high range from 49 to $66 \%$. Secondly, with operating pressure's increasing and mercury's gradually entering into small pores, there is an apparently difference between permeability and saturation. The cumulative permeability contribution almost keeps still. However, the cumulative mercury saturation keeps increasing. The difference indicates that the relatively small pores had little effect on the permeability, but had some reservoir capacity. By analyzing the mercury-injection experiments in the study area, it is found that about $29.5 \%$ of the average mercury saturation is mostly controlled by small pores.

By comparing characteristics of mercury intrusion curves between different types, permeability contribution curves shift to the left as the permeability of the sample decreases, reflecting that the larger the permeability, the larger the relative large pore proportion. The permeability of the study area is mostly dominated by pores with radius larger than $\mathrm{R}_{50}-\mathrm{R}_{60}$.

\section{Water driving features}

The micro-water-flooding experiment of real cores for three different types of reservoirs is executed to obtain the oildriven efficiency of I, II and III (Table 3). The average ending average oil-driven efficiency of 4 samples is $44.4 \%$, and the oil-driven efficiency gradually decreases with the deterioration of their pore structure. After observing the water 
Table 2 Statistical table for classification of pore structure parameters of high-pressure mercury injection

\begin{tabular}{|c|c|c|c|c|c|c|}
\hline \multirow[t]{2}{*}{ Parameter type } & \multicolumn{2}{|l|}{ Type I } & \multicolumn{2}{|l|}{ Type II } & \multicolumn{2}{|l|}{ Type III } \\
\hline & Distribution range & Average value & Distribution range & Average value & Distribution range & Average value \\
\hline Porosity $/ \%$ & $9.4-12.3$ & 11.22 & $8.8-14.1$ & 10.48 & $7.1-17.4$ & 9.53 \\
\hline $\begin{array}{l}\text { Permeability } / \times 10-3 \\
\quad \mu \mathrm{m} 2\end{array}$ & $0.47-1.02$ & 0.84 & $0.15-0.76$ & 0.5 & $0.09-0.52$ & 0.24 \\
\hline $\begin{array}{l}\text { Displacement pressure/ } \\
\text { MPa }\end{array}$ & $0.15-0.39$ & 0.28 & $0.37-0.98$ & 0.69 & $1.12-2.76$ & 1.39 \\
\hline $\begin{array}{l}\text { Maximum mercury } \\
\text { saturation/\% }\end{array}$ & $84.92-90.56$ & 88.2 & $80.24-95.26$ & 86.52 & $80.58-87.35$ & 84.47 \\
\hline Median pressure/MPa & $0.93-4.89$ & 2.89 & $3.89-14.13$ & 7.2 & $16.07-20.76$ & 19.96 \\
\hline Median radius/ $\mu \mathrm{m}$ & $0.15-0.32$ & 0.38 & $0.05-0.19$ & 0.12 & $0.035-0.046$ & 0.041 \\
\hline $\begin{array}{l}\text { Main pore-throat radius/ } \\
\mu \mathrm{m}\end{array}$ & $0.43-1.56$ & 0.76 & $0.11-0.57$ & 0.34 & $0.06-0.41$ & 0.18 \\
\hline $\begin{array}{l}\text { Average pore-throat } \\
\text { radius } / \mu \mathrm{m}\end{array}$ & $0.29-0.49$ & 0.38 & $0.13-0.37$ & 0.21 & $0.06-0.12$ & 0.09 \\
\hline $\begin{array}{l}\text { Maximum pore-throat } \\
\text { radius } / \mu \mathrm{m}\end{array}$ & $1.63-6.13$ & 2.35 & $0.65-1.62$ & 1.08 & $0.25-0.65$ & 0.58 \\
\hline Sorting coefficient & $2.34-2.7$ & 2.53 & $1.67-3.06$ & 2.35 & $2.24-2.94$ & 2.59 \\
\hline Mean coefficient & $9.63-10.68$ & 10.22 & $9.62-12.4$ & 10.99 & $10.6-11.63$ & 11.31 \\
\hline Skewness coefficient & $1.49-1.93$ & 1.72 & $0-1.88$ & 1.5 & $1.52-1.64$ & 1.6 \\
\hline Coefficient of variation & $0.23-0.27$ & 0.25 & $0.15-0.32$ & 0.22 & $0.19-0.28$ & 0.23 \\
\hline Main pore types & \multicolumn{2}{|c|}{$\begin{array}{l}\text { Intergranular pores, dissolved pores, } \\
\text { intergranular pores - dissolved pores }\end{array}$} & \multicolumn{2}{|c|}{$\begin{array}{l}\text { Intergranular pores-dissolved pores, } \\
\text { dissolved pores, micropores }\end{array}$} & \multicolumn{2}{|c|}{$\begin{array}{l}\text { Dissolved pores-micropores, } \\
\text { micropores }\end{array}$} \\
\hline Pore structure type & \multicolumn{2}{|c|}{$\begin{array}{l}\text { Low displacement pressure-micro- } \\
\text { throat type }\end{array}$} & \multicolumn{2}{|c|}{$\begin{array}{l}\text { Medium displacement pressure-micro- } \\
\text { throat type }\end{array}$} & \multicolumn{2}{|c|}{$\begin{array}{l}\text { High displacement pressure- } \\
\text { micro-throat type }\end{array}$} \\
\hline Proportion & \multicolumn{2}{|l|}{$20.9 \%$} & \multicolumn{2}{|l|}{$54.1 \%$} & \multicolumn{2}{|l|}{$25 \%$} \\
\hline
\end{tabular}

driving features in the process of water injection, 3 kinds of the water flooding are summarized: the uniform driving (Fig. 6a), the reticular driving (Fig. 6b) and the fingering driving (Fig. 6d). The water driving result worsens one by one.

(1) For type I reservoir, the oil-driven efficiency during the anhydrous period can reach $46.39 \%$, and the oildriven efficiency in the end is $61.78 \%$. Its flooding type is mainly the uniform driving. Water enters pores under small pressure and moves forward evenly. The water-flooding area increases steadily, and the driving efficiency is high. Due to the high permeability of such reservoirs and large pore radius, water runs in the middle part of pores and then squeezes and drains crude oil, leaving the residual oil attached to the surface of pores as the oil film (Fig. 6a).

(2) For type II reservoir, the oil-driven efficiency during the anhydrous period can reach $28.12 \%$, and the driving type mainly includes mesh and fingering. Due to the complex pore structure, water preferentially enters large pores for their small resistance, mostly resulting in fingering driving. The oil-driven efficiency in the end is $43.24 \%$. In the late period, with the increase in injection pressure, water enters some small pores and mesh seepage channels gradually form, while the uniform flooding can also happen in some samples with a better pore connectivity. Because of the complex pore structure of such reservoirs, there are major differences in the flooding speed between large and small pores. If water in large pores runs faster than in small pores, oil expelled from small pores would be captured by water in large pores, forming an special phenomenon called "water block" (Guo et al. 2012; Wang et al. 2010). If water in small pores runs faster than in large pores, oil in large pores would be ringed by water in small pores and form oil droplets. There are two kinds of the residual oil: water-locked oil and oil droplets (Fig. 6b).

(3) For type III reservoir, the oil-driven efficiency during the anhydrous period can reach $19.76 \%$, and the driving type is mainly the fingering. Due to the low permeability and bad pore connectivity, water only enters a few pores even at the high pressure, showing a unidirectional fingering phenomenon. The average oil-driven efficiency in the end is $29.34 \%$, which is much lower than that of I and II reservoirs. Owing to the small pore 


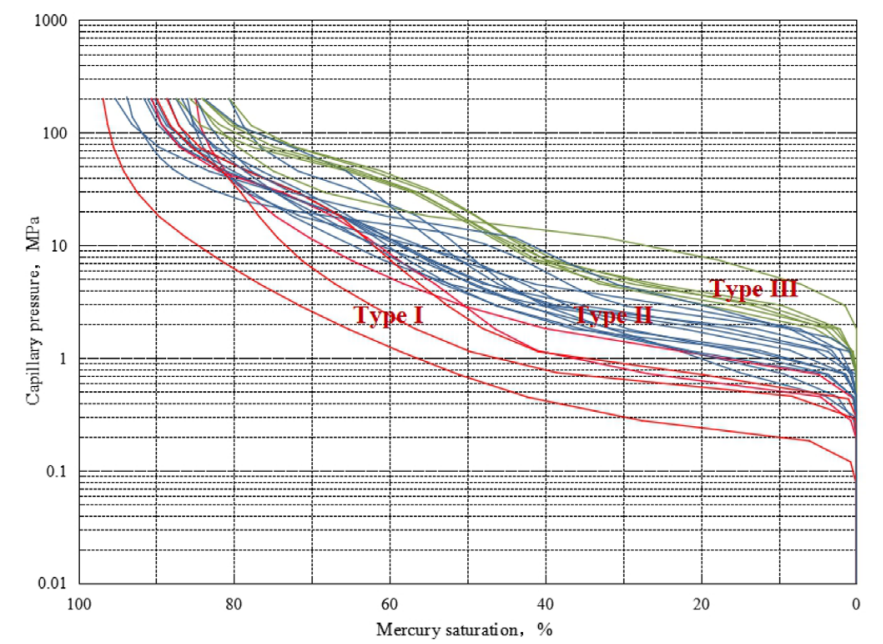

a. Characteristic graphs of mercury injection curves of different types

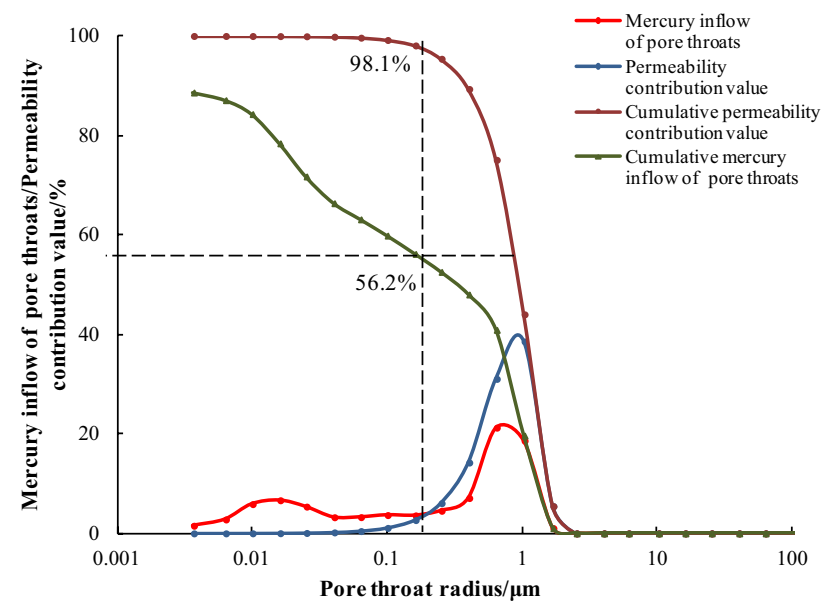

c. Type II , Y182, 2101.2m

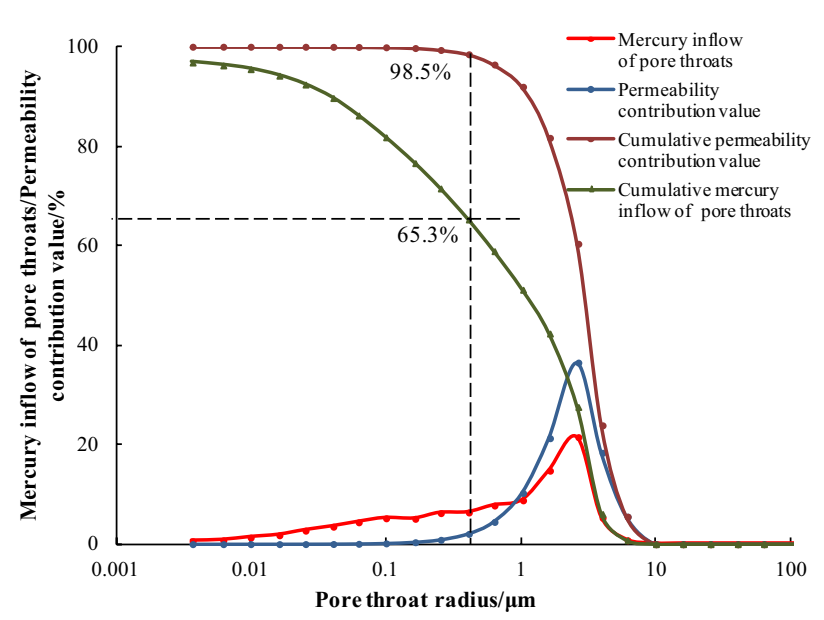

b. Type I , A36, 1945.2m

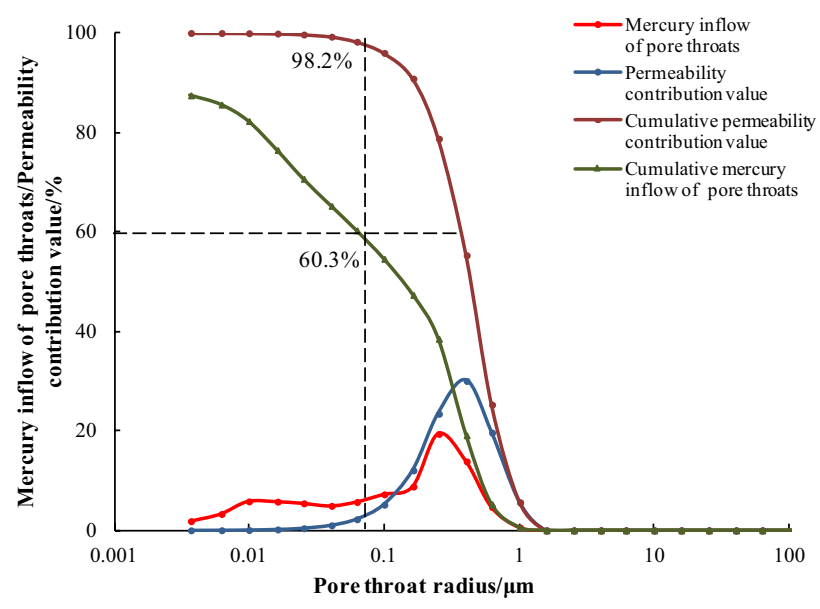

d. Type III, A211, 1922.6m

Fig. 5 The capillary pressure curve and pore-throat distribution characteristics of different pore structure types

radius and frequently high plugging of pores, the water driving area narrows, easily living a large area of contiguous residual oil (Fig. 6c).

\section{Factors of oil-driven efficiency}

\section{(1) Porosity and Permeability}

The correlation between porosity-permeability and the final oil flooding efficiency reveals their influence in oil flooding efficiency. Porosity has no obvious correlation with the final oil flooding efficiency (Figure 7a). Permeability, while, has a strong positive correlation with the final oil-driven efficiency, and its correlation coefficient $R^{2}$ is 0.6518 (Figure $7 b$ ), indicating that the permeability can better reflect the seepage characteristics of reservoir rocks. The correlation between the permeability and flooding efficiency, however, is not very strong enough, meaning that some small pores are unable to maximum their seepage ability and their contribution to the oil flooding efficiency. Thanks to the bad connectivity and complex configuration of pores, the influence of macroscopic physical properties on the oil-driven efficiency is much weak. Thus, there are some unusual phenomenon: the high permeability with the 


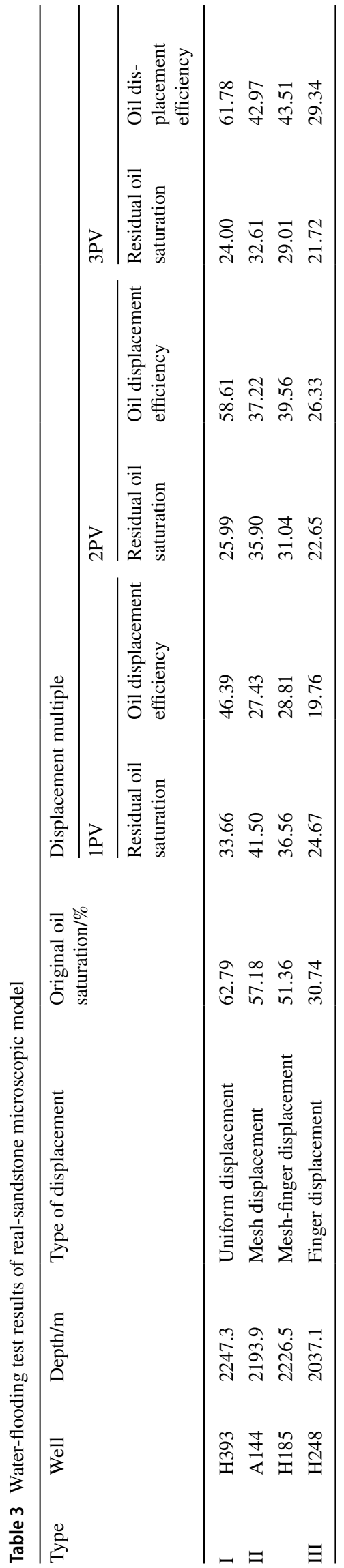

low driving efficiency and the low permeability with the high driving efficiency.

\section{(2) Pore Types}

The pore structure has an obvious impact on the oildriven efficiency. The pore structure of four samples in experiments can be divided into three types: intergranular pores, dissolved pores and micropores. Samples developing intergranular pores have a high oil-driven efficiency because water floods in uniform and mesh way and the driving area is generally wide. Samples having dissolved pores obtain a middle-level oil flooding efficiency for the water flooding mostly in mesh and fingering way. It is worth noting that the oil flooding efficiency increases apparently when the water volume triples, but it grows a little by one multiple. The lowest oil-driven efficiency lies in samples developing small intercrystalline pores, which are often formed by clay minerals. Therefore, with the increase in water volume, its oil-driven efficiency has not been significantly improved.

\section{(3) Pore Heterogeneity}

The heterogeneity of pores is the key factor affecting the oil-driven efficiency. The stronger the heterogeneity, the largely the seeping ability between pores differs. A lot of oil is often bypassed and hardly has the chance of being driven away by water which mainly go across high speed channels formed by large pores, resulting in a significant reduction in oil-driven efficiency.

According to the correlation of pore parameters and the oil-driven efficiency, there are three strong positive correlations between the oil-driven efficiency and the mainstream pore radius, the average pore radius and the median radius, and their correlation coefficient $R^{2}$ is $0.4555,0.6309$ and 0.69 , respectively (Fig. $8 \mathrm{a}-\mathrm{c}$ ). It shows that the pore radius has a strong impact on the efficiency of water driving. With increase in the pore radius, the permeability, oil flooding efficiency and water-flooding range are getting larger. The correlation between the oil flooding efficiency and the pore sorting coefficient presents negative, and the correlation coefficient $R^{2}$ is 0.3769 (Fig. 8d). The sorting coefficient represents the heterogeneity of pores. The larger the sorting coefficient, the stronger the heterogeneity, and the lower the oil-driven efficiency. The large sorting coefficient is mainly caused by the filling of clay minerals and other matrix which are serious damage on the connectivity of pores.

\section{(4) Water Multiple}

According to the correlation between the oil-driven efficiency and the water flooding multiple from the experiment, the oil flooding efficiency increases with the increase in the 


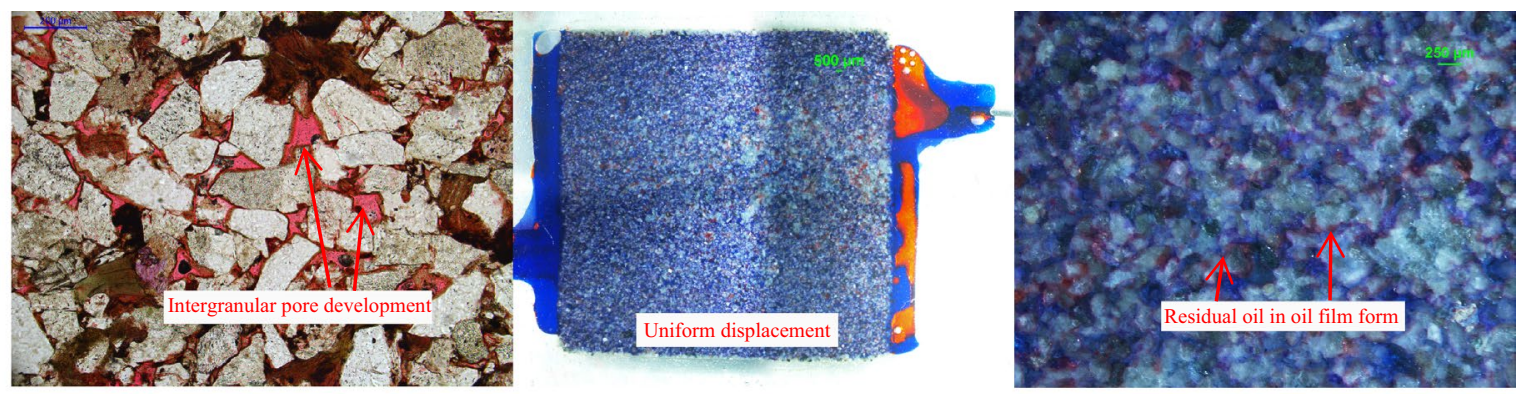

a. H393, intergranular pore development, uniform displacement, the final oil displacement efficiency of $61.78 \%$

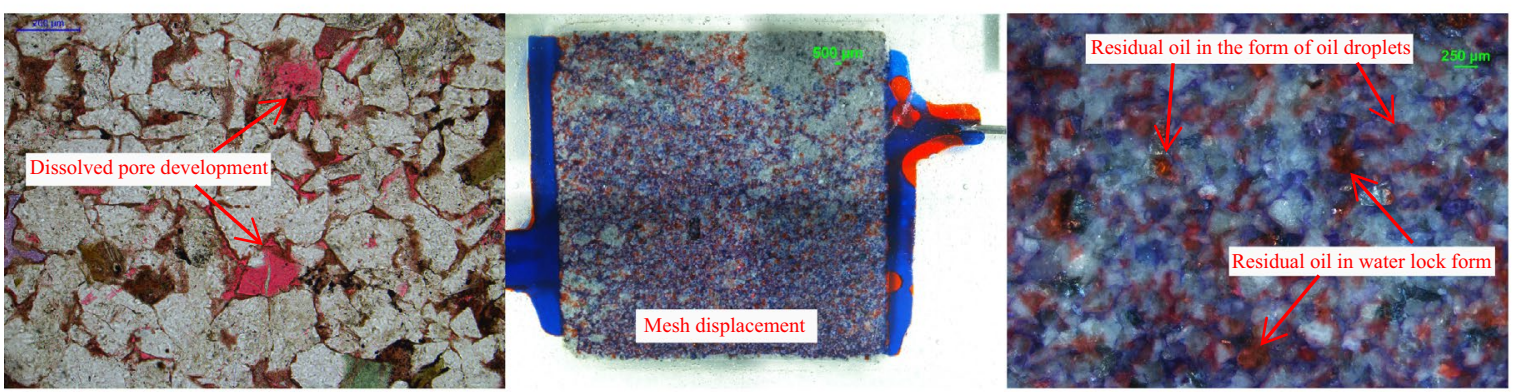

b. A144, dissolved pore development, mesh displacement, final oil displacement efficiency $42.97 \%$

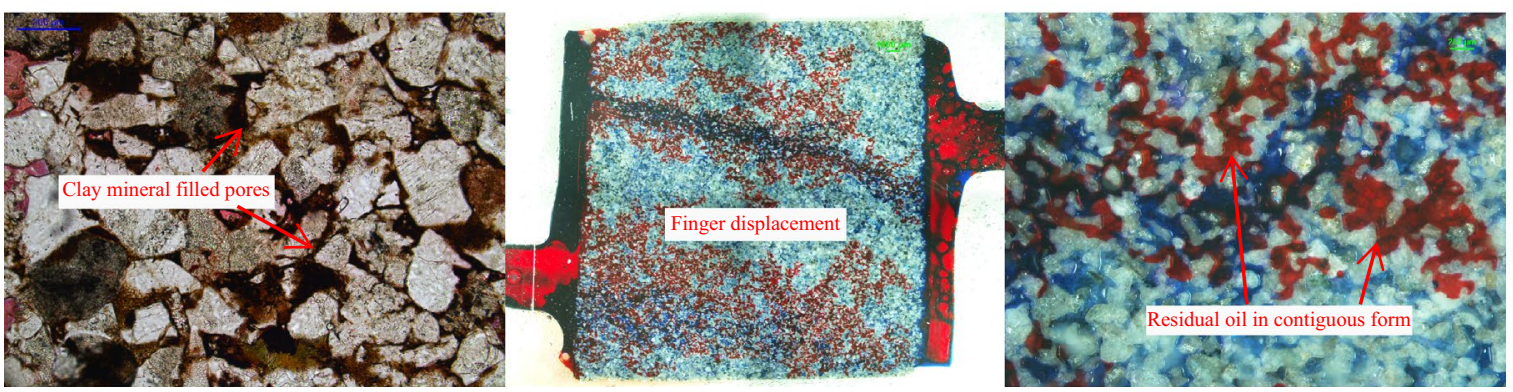

c. H248, Clay mineral filled pores, dominated by micropores, finger displacement, $29.34 \%$

Fig. 6 Models of different water-flooding types

water multiple. The oil flooding efficiency grows greatly before the water volume reach the double multiple, but then seldom grows with the multiple increasing from double to triple (Fig. 9). That means there is one dividing point, beyond which the growth of water volume hardly help more oil getting out. Therefore, it is vital to make a reasonable water flooding multiple for a better performance of the water flooding.

\section{(5) Water Driving Pressure}

From the water driving experiment data, there is a positive correlation between the water driving pressure and its driving speed. The higher the pressure, the faster the water runs. With the increase in the water driving pressure, the water's ability to enter small pores grows strong and more and more oil can be flooded out of small pores, leading to the promotion of the oil-driven efficiency. However, in the 


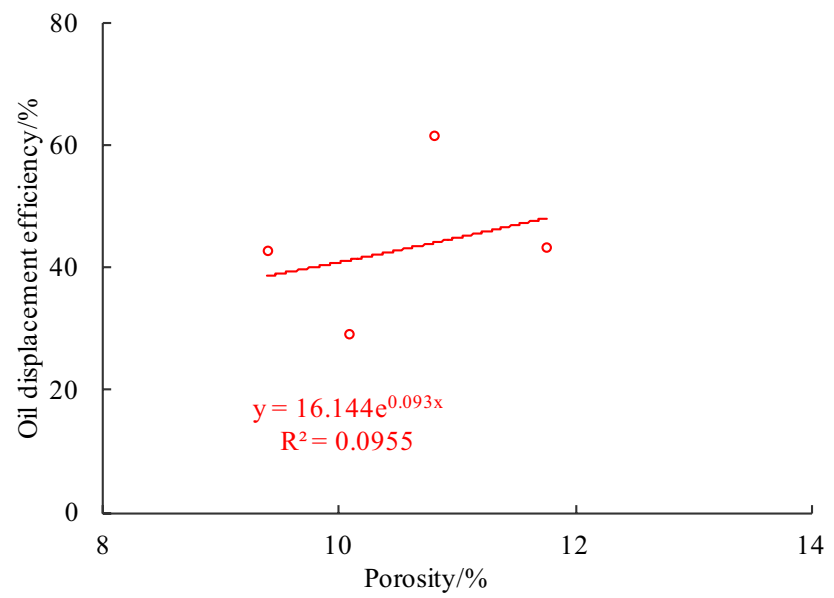

a. Correlation diagram between porosity and oil displacement efficiency

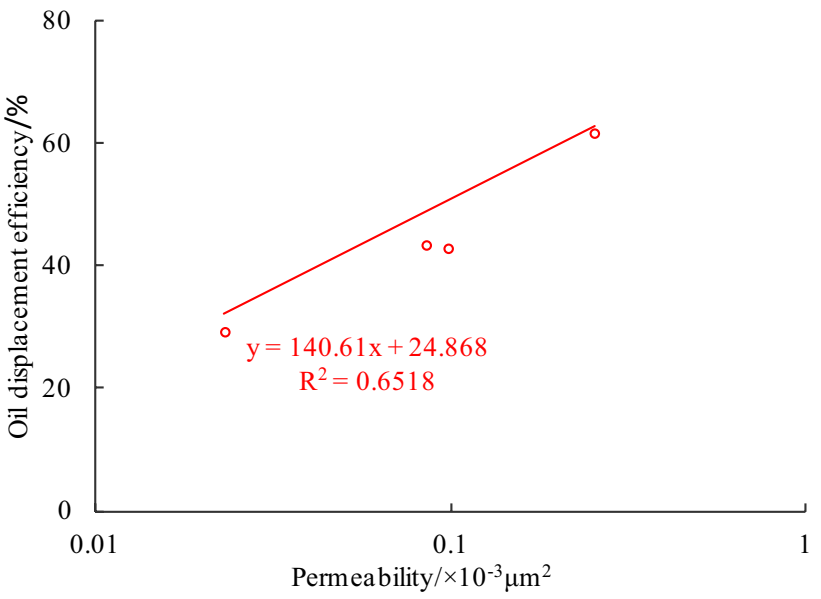

b. Correlation diagram between permeability and oil displacement efficiency

Fig. 7 Correlation diagram between physical properties and oil displacement efficiency

early stage, the water driving pressure has little effects on the seepage of small pores because water mainly flows through large pores and seldom enters small ones. Therefore, in general, the water driving pressure works a lot in the middle or late stage.

\section{Conclusions}

(1) Rock types of Chang 6 tight reservoir in Ordos Basin mainly consist of feldspar sandstone and lithic-feldspar sandstone, and the main clastic components are composed of quartz, feldspar and lithic. The matrix content is high, mainly including chlorite, kaolinite, illite, iron calcite and siliceous. The average porosity and permeability are $10.67 \%$ and $0.53 \times 10^{-3} \mu \mathrm{m}^{2}$. The pore types mainly is made up of intergranular pores and feldspar dissolved pores, and their average surface porosity is $4.33 \%$.

(2) The permeability contribution curves of samples shift to the left as their permeability decreases, indicating that the larger the permeability is, the larger the large pore throats account for. The permeability of the study area is mostly contributed by large pores with the radius greater than $\mathrm{R}_{50}-\mathrm{R}_{60}$. Type II reservoir is the key target of subsequent exploration and development.

(3) (3)The oil flooding efficiency of type I reservoir in the study area is the highest and is dominated by the uniform driving living the residual oil attached to the surface of grains as the oil film. The oil-driven efficiency of type II reservoir, lower than that of type I reservoir, is dominated by mesh and fingering driving, and the residual oil is locked or isolated by water, forming water-locked oil and oil droplets. The oil-driven efficiency of type III reservoir is the lowest and mainly consists of the finger driving, easily forming amount of contiguous residual oil after water driving.

(4) The correlation between the oil-driven efficiency and permeability in the study area is strong, and the correlation between the oil-driven efficiency and porosity is weak. Clay minerals' filling and blocking pores mostly result in the complex and bad pore connectivity. The water driving pressure should be adjusted elaborately and reasonable to be accustomed into different stages of water driving. The radius of pores and their distribution feature are the key factors affecting the oil-driven efficiency. 


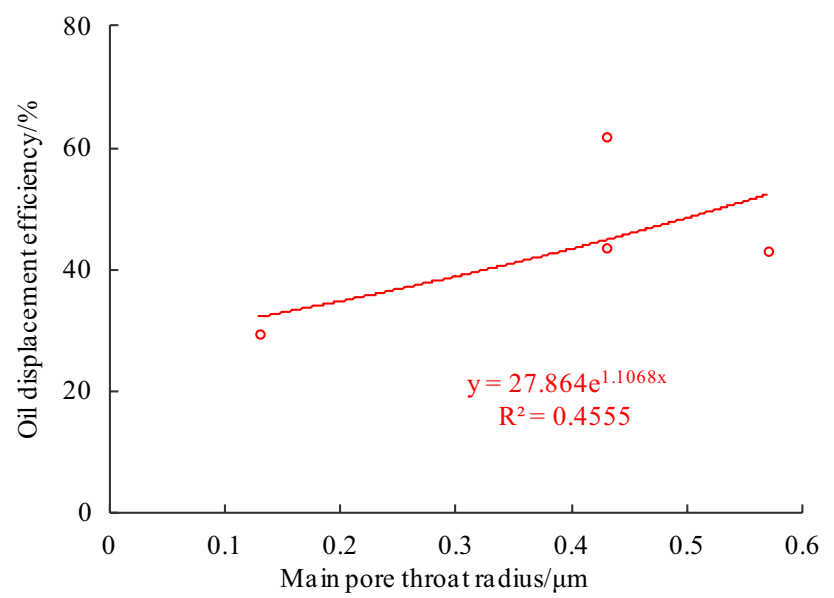

a. Correlation diagram between main pore throat radius and oil displacement efficiency

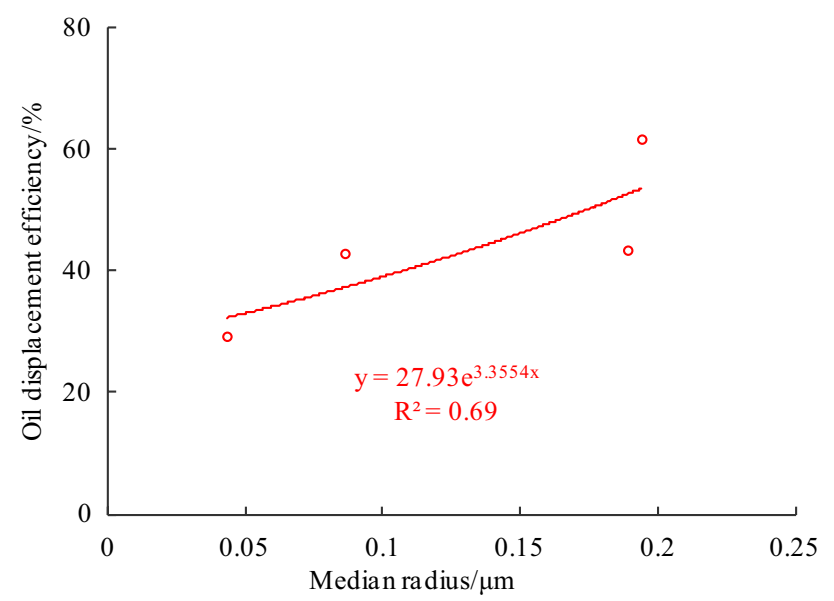

c. Correlation diagram between median radius and oil displacement efficiency

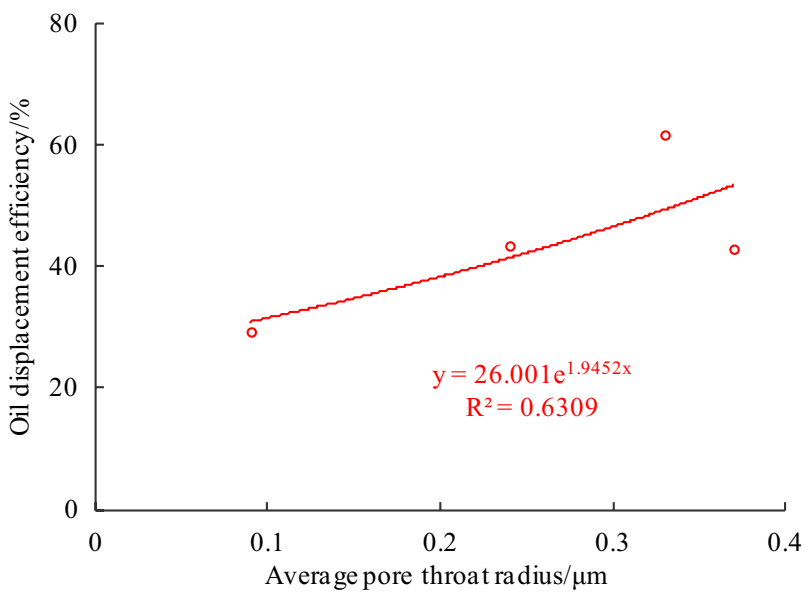

b. Correlation diagram between average pore throat radius and oil displacement efficiency

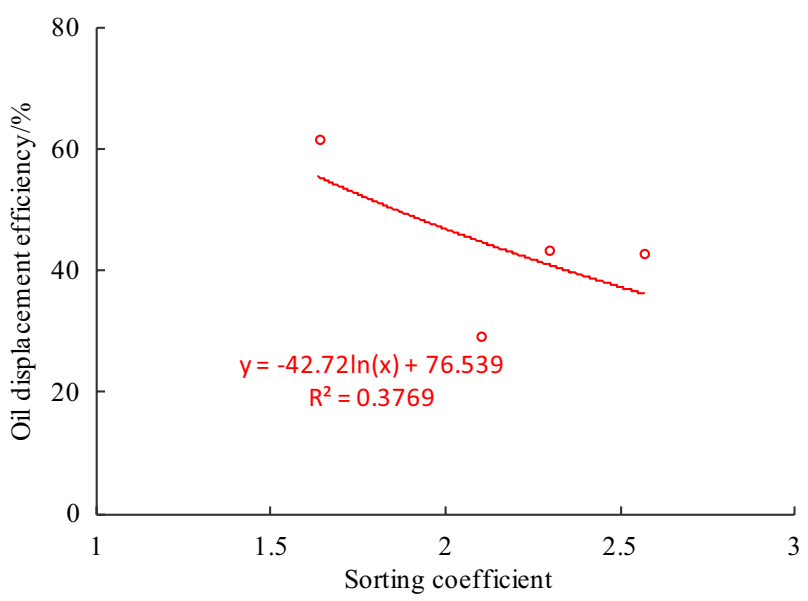

d. Correlation diagram between Sorting coefficient and oil displacement efficiency

Fig. 8 Correlation between pore structure parameters and oil displacement efficiency

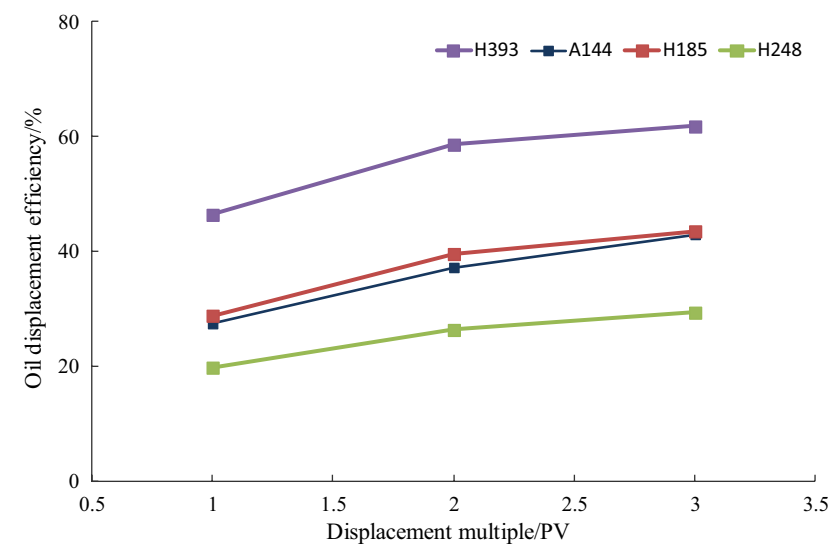

Fig. 9 Oil displacement efficiency under different body displacement multiples
Acknowledgements This work is funded by National Science and Technology Major Project of the Ministry of Science and Technology of China (2017ZX05013004; 2017ZX05069003).

Funding National Science and Technology Major Project of the Ministry of Science and Technology of China(2017ZX05013004; 2017ZX05069003).

\section{Declarations}

Conflict of interest On behalf of all authors, Shi Jian states that there is no conflict of interest.

Open Access This article is licensed under a Creative Commons Attribution 4.0 International License, which permits use, sharing, adaptation, distribution and reproduction in any medium or format, as long as you give appropriate credit to the original author(s) and the source, provide a link to the Creative Commons licence, and indicate if changes were made. The images or other third party material in this article are 
included in the article's Creative Commons licence, unless indicated otherwise in a credit line to the material. If material is not included in the article's Creative Commons licence and your intended use is not permitted by statutory regulation or exceeds the permitted use, you will need to obtain permission directly from the copyright holder. To view a copy of this licence, visit http://creativecommons.org/licenses/by/4.0/.

\section{References}

Bai YY, Sun W, Han J (2018) Study on the characteristics of water displacing oil and main controlling factors in chang 6 reservoir in Huaqing oilfield of Ordos Basin. J Chin Electron Microsc Soc 37(4):348-359

Fu JH, Yu J, Xu LM, Niu XB, Feng SB, Wang XJ et al (2015) New progress in exploration and development of tight oil in Ordos Basin and main controlling factors of largescale enrichment and exploitable capacity. China Pet Explor 20(5):9-19

Gao H, Xie W, Yang JP, Zhang C, Sun W (2011) Pore throat characteristics of extra-ultra low permeability sandstone reservoir based on constantrate mercury penetration technique. Pet Geol Exp 33(2):206-211

Guo YR, Liu JB, Yang H, Liu Z, Fu JH, Yao JL et al (2012) Hydrocarbon accumulation mechanism of low permeable tight lithologic oil reservoirs in the Yanchang formation, Ordos Basin. China Pet Explor Dev 39(4):417-425

Huang X, Li T, Gao H, Zhao J, Wang C (2019a) Comparison of $\mathrm{SO}_{2}$ with $\mathrm{CO}_{2}$ for recovering shale resources using low-field nuclear magnetic resonance. Fuel 245:563-569

Huang X, Li TT, Wang XZ, Gao H, Ni J (2019b) Distribution characteristics and its influence factors of movable fluid in tight sandstone reservoir: a case study from Chang 8 oil layer of Yanchang formation in Jiyuan oilfield. Ordos Basin Acta Pet Sinica 40(5):557-567

Jia CZ, Zheng M, Zhang YF (2012) Unconventional hydrocarbon resources in China and the prospect of exploration and development. Pet Explor Dev 39(2):129-136

Li HB, Guo HK, Yang ZM, Wang XW (2015a) Tight oil occurrence space of Triassic Chang 7 member in Northern Shaanxi area, Ordos Basin. NW China Pet Explor Dev 42(3):396-400

Li ZX, Qu XF, Liu WT, Lei QH, Sun HL, He YA (2015b) Development modes of Triassic Yanchang formation Chang 7 member tight oil in Ordos Basin. NW China Pet Explor Dev 42(2):217-225
Quan HH, Zhu YS, Zhang HJ, Li L, Shao F, Zhang Z (2011) Reservoir pore structure and micro-flow characteristics of waterflooding: a case study from Chang 6 reservoir of Wangyao block in Ansai Oilfield. Oil GasGeol 32(54):952-964

Wang RF, Sun W (2010) Main controls for oil displacement efficiency by the micro model water flooding experiment in ultra-low permeability sandstone reservoir. Pet Geol Exp 32(1):93-97

Yang Z, Fu JH, Guo QL, Lin SH, Chen NS, Pan SQ et al (2017) Discovery, characteristics and resource potential of continental tight oil in Triassic Yanchang formation Ordos Basin. China Pet Explor 22(6):9-15

Yang H, Li SX, Liu XY (2013) Characteristics and resource prospects of tight oil and shale oil in Ordos Basin. Acta Pet Sinica 34(1):1-11

You Y, Niu XB, Feng SB, Wang F, Wang CY, Li WC (2014) Study of pore features in Chang 7 tight oil reservoir, Yanchang layer, Ordos Basin. J China Univ Pet (Ed Nat Sci) 38(6):18-23

Zhang X, Ren DZ, Ren QY, Huang H, Liu DK, Qu XF (2015) The feature of the microscopic pore structure and its influence on oil displacement efficiency in Chang 6 reservoir in Jiyuan Oilfield of Ordos Basin. J Northwest Univ (Nat Sci Ed) 45(2):284-295

Zhang F, Sun W, Zhang X, Hu B, Ma M, Wang B (2017) The application of electron microscope in the oilfield development: in the case of Chang 6 reservoir in Ban Qiao-He Shui area. J Chin Electron Microsc Soc 36(4):358-369

Zhou JJ (2017) Characteristics of the pore-throat structures and their influences on the waterflooded oil micro-features for Chang 8 reservoir in Pingbei block of Yanchang Oilfield. Pet Geol Oilfield Dev Daqing 36(5):68-79

Zou CN (2011) Unconventional petroleum geology. Geological Publishing House, Beijing

Zou CN, Tao SZ, Yuan XJ, Zhu RK, Dong DZ, Li W et al (2009) Global importance of "continuous" petroleum reservoirs: accumulation, distribution and evaluation. Pet Explor Dev 36(6):669-682

Zou CN, Tao SZ, Yang Z (2012) New advance in unconventional petroleum exploration and research in China. Bull Mineral Petrol Geochem 31(4):312-322

Publisher's Note Springer Nature remains neutral with regard to jurisdictional claims in published maps and institutional affiliations. 